МИНИСТЕРСТВО ОБРАЗОВАНИЯ И НАУКИ РОССИЙСКОЙ ФЕДЕРАЦИИ

ТОМСКИЙ ГОСУДАРСТВЕННЫЙ УНИВЕРСИТЕТ

\title{
МАТЕРИАЛЫ
}

VIII Международной молодежной научной конференции

«МАТЕМАТИЧЕСКОЕ

И ПРОГРАММНОЕ ОБЕСПЕЧЕНИЕ

ИНФОРМАЦИОННЫХ, ТЕХНИЧЕСКИХ

И ЭКОНОМИЧЕСКИХ СИСТЕМ»

Томск, 26-30 мая 2021 г.

Под общей редакиией И.С. Шмырина

Томск

Издательство Томского государственного университета 2021 


\title{
VII. ТЕОРЕТИЧЕСКИЕ И ПРИКЛАДНЫЕ АСПЕКТЫ РАЗРАБОТКИ ПРОГРАММНОГО ОБЕСПЕЧЕНИЯ И DEVOPS-ИНЖЕНЕРИИ
}

DOI: $10.17223 / 978-5-907442-42-9-2021-28$

\section{РАЗРАБОТКА И АНАЛИЗ ПРОГРАММНОЙ СИМУЛЯЦИИ ЭВОЛЮЦИОНИРУЮЩЕЙ ВОДНОЙ ЭКОСИСТЕМЫ С ПРОЦЕДУРНОЙ ГЕНЕРАЦИЕЙ ЛАНДШАФТА}

\author{
Березовский Н.В., Буторина Н.Б. \\ Томский государственный университет \\ hemenbgmb@gmail.com,nnatta07@mail.ru
}

\section{Введение}

С развитием ЭВМ у человека появилась возможность производить ресурсоемкие вычисления в различных сферах деятельности. Люди стали имитировать математические модели, позволяющие им лучше понимать природу тех или иных явлений, таких как движение тектонических плит, распространение инфекции, процесс эволюции. Например работа Карла Симса "Evolved virtual creatures" [1], представляющая из себя симуляцию и исследование эволюции Дарвина виртуальных блочных существ, которым давались различные задания. Программные гены лучших из них отбирали, комбинировали и подвергали мутации, чтобы повторно пройти тестирование. Некоторые существа вырабатывали стратегии, схожие с теми, что есть в нашем мире. Свое место в этой сфере нашли и симуляции различного рода экосистем, например, знаменитая “Игра в жизнь” Джона Конвея [2], представляющая из себя клеточный автомат с определенным набором правил, поведение которого очень схоже с развитием популяций примитивных организмов.

Оказалось, что на основе клеточных автоматов можно моделировать явления из физики, химии, биологии или строить интересные фрактальные узоры, схожие с теми, которые мы можем встретить в природе. Некоторые же алгоритмы, такие как шум Перлина, направлены именно на генерацию случайных шаблонов. В основном он находит применение в области компьютерной графики, а впервые был использован в киноиндустрии для процедурной генерации текстур. Он полезен при имитации случайных структур из природы, таких как туман, облака, дым, огонь или ландшафт.

\section{1. Постановка задачи}

Цель работы: Разработать симуляцию эволюционирующей водной экосистемы, обитателями которой являются водоросли, нехищные и, в противоположность последним, хищные рыбы. В процессе естественного отбора они будут эволюционировать, приобретая те или иные характеристики, позволяющие им лучше приспосабливаться к меняющимся условиям. На популяции рыб будет исследовано воздействие ландшафта, наличие или отсутствие хищников, условия избытка и дефицита пропитания по отдельности и в композиции.

\section{2. Разработка искусственного интеллекта рыб}

Существуют разные подходы к разработке искусственного интеллекта, которые отличаются сложностью реализации и применимостью, например, деревья решений, автоматный подход, деревья поведений, системы, основанные на полезности или на машинном обучении [3]. 
Для реализации искусственного интеллекта рыб был выбран автоматный подход, т.к. для данной задачи он является оптимальным вариантом по сложности и возможностям. Ниже будет описан набор состояний и характеристики, которые определяют их смену. Для начала нужно определить параметры объекта:

- Размер - влияет на количество энергии и способность к размножению.

- Скорость - быстрота движения рыбы. Влияет на расход энергии.

- Энергия - способность рыбы к действиям. Если она кончается, то рыба умирает.

- Время до следующего размножения - размножение с определённым периодом.

- Минимальный необходимый размер для размножения - данный параметр позволяет ограничить размножение слишком маленьких и слабых особей.

- Разброс плавания - величина, на которую объект будет уплывать от текущей позиции.

· Страх к другим рыбам - характеризует вероятность, с которой особь будет уплывать от незнакомой ей рыбы.

· Коэффициент потери энергии - коэффициент, на который умножаются все затраты и восполнения энергии.

Далее можно определить возможные состояния рыбы. У травоядной особи (рис. 1):

1. Бездействует (Idle) - плавает и анализирует окружение.

2. Ест (Eating) - приближается к растению, чтобы пополнить запас энергии.

3. Размножается (Mating) - приближается к партнеру, чтобы передать гены.

4. Скрывается (Hiding) - уплывает от попавшего в область видимости хищника.

Для хищной рыбы (рис. 2):

1. Бездействует (Idle) - плавает с низким разбросом плавания, сохраняя энергию.

2. Ищет добычу (Searching) - плавает и анализирует окружение.

3. Ест (Eating) - приближается к добыче, чтобы атаковать и съесть.

4. Размножается (Mating) - подплывает к партнеру для передачи генов.

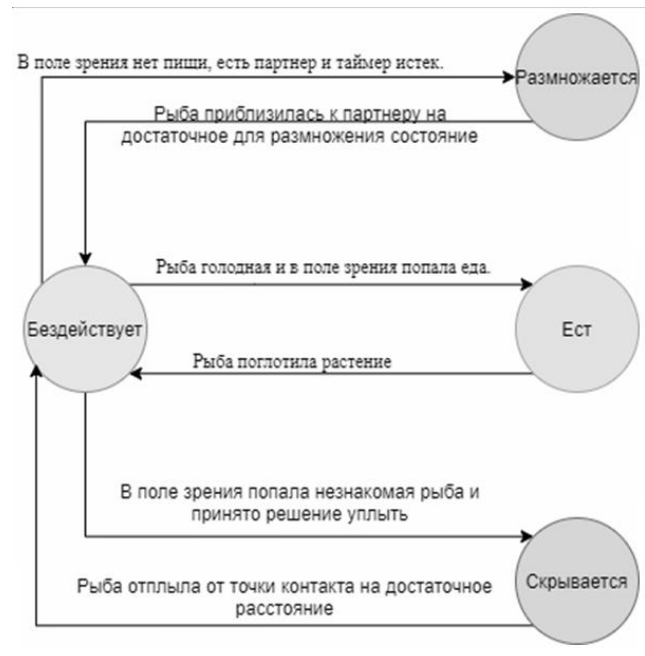

Рис. 1. Переходы состояний травоядной рыбы

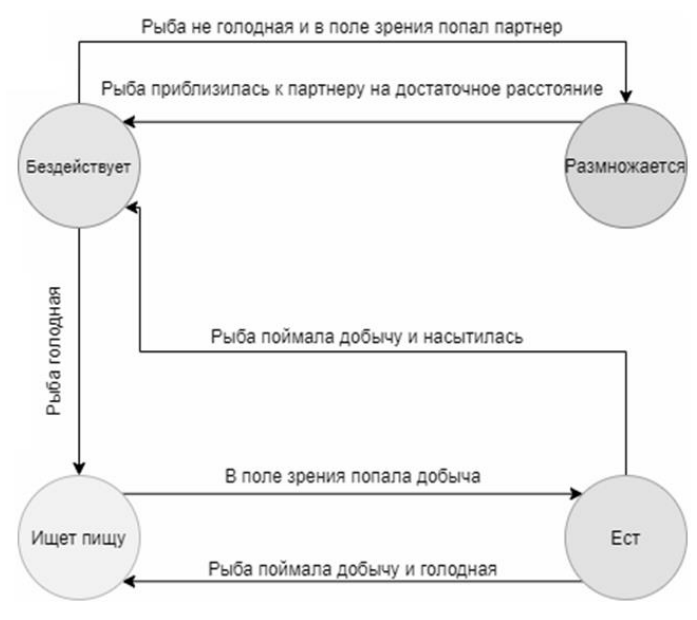

Рис. 2. Переходы состояний хищной рыбы

Параметры хищных и нехищных рыб сильно отличаются. У хищных рыб запас энергии сильно больше и они могут долго не есть. Размножение происходит медленнее. Разброс плавания дублируется на состояния поиска пищи и сохранения энергии. По понятным причинам скорость передвижения хищных рыб также больше.

Особь будет анализировать окружение с помощью зрения, которое основано на методе бросания лучей [4]. Для реализации этого метода нужно сгенерировать векторы, расположенные вокруг окружности и направленные наружу. Затем для каждого вектора применяется метод бросания лучей, т.е. проверяется факт пересечения этим вектором 
других объектов, а именно - рыб, водорослей или поверхности ландшафта. На основе пересечений, текущего состояния и текущих значений параметров особи и принимается решение о смене состояния.

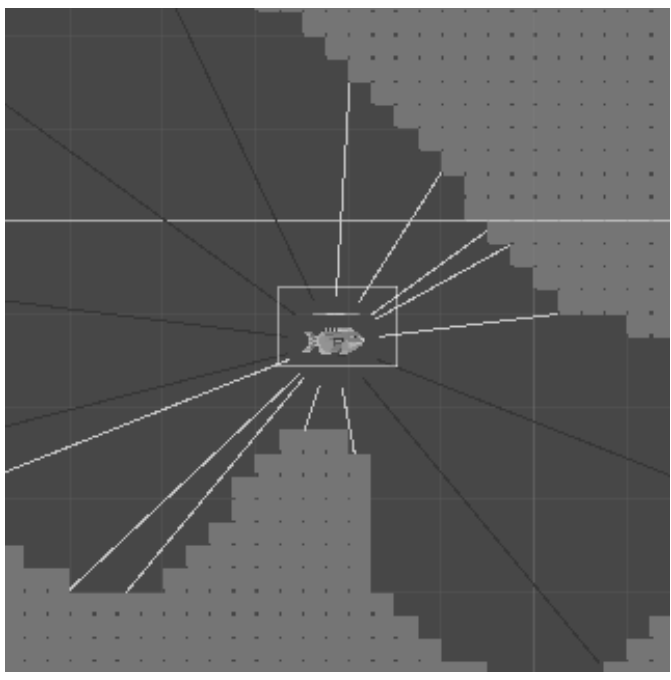

Рис. 3. Бросание лучей в поверхность ландшафта

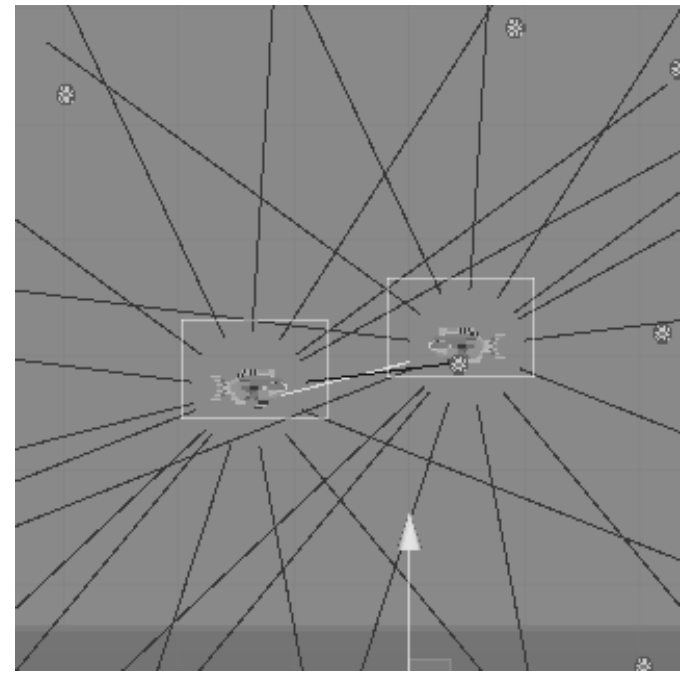

Рис. 4. Бросание лучей для определения объектов

\section{3. Разработка процедурной генерации ландшафта}

Случайные числа, сгенерированные компьютером можно разбить на 2 класса случайные и псевдослучайные. Первая категория использует случайность, основанную на природе, например, числа генерируются на основе датчиков, считывающих космический шум. Вторая использует различные алгоритмы для генерации псевдослучайных чисел, например, линейный конгруэнтный метод. Отличительной особенностью второй категории является использование числа, на основе которого генерируется псевдослучайная последовательность, его, как правило, называют зерном. Свое применение псевдослучайные числа нашли и в генерации различных структур.

Создавать структуры на основе псевдослучайных чисел можно с помощью заранее заготовленных элементов, определяя их расположение с помощью набора правил, или полностью с нуля, используя процедурную генерацию [5].

В данной работе целью является генерация ландшафта, похожего на морское дно, или на подводную систему пещер. Эта задача была разбита на 2 этапа - генерация дна и системы пещер. На первом этапе генерируется пустая матрица, размеры которой соответствуют требуемой длине и высоте ландшафта. Элементы матрицы заполняются в соответствии с данными, сгенерированными шумом Перлина. Вариативность ландшафта достигается за счет использования зерна для шума (рис. 5).

На втором этапе на матрицу накладывается 2-хмерный шум. Размер пещер можно регулировать, накладывая только тот шум, который выше заданного пользователем значения (рис. 6).

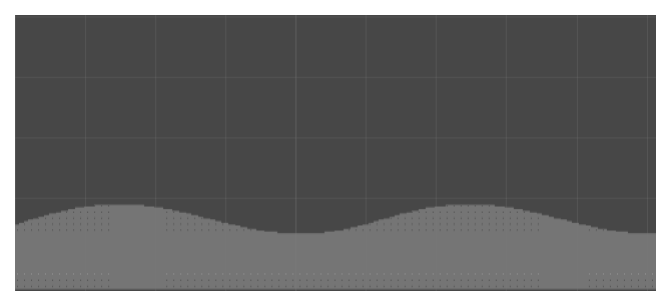

Рис. 5. Ландшафт на первом этапе генерации

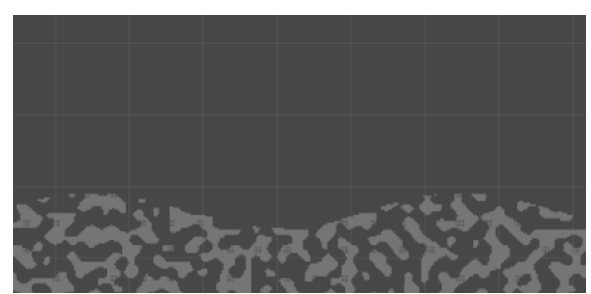

Рис. 6. Ландшафт на втором этапе генерации 


\section{4. Введение эволюции рыб}

Эволюция популяции рыб будет основана на идеях генетического алгоритма. Идея генетического алгоритма тесно связана с основными положениями теории Дарвина. Для того, чтобы естественный отбор происходил так, как это происходит в природе, необходимо присутствие следующих элементов: наследственность, изменчивость и естественный отбор [6].

В общем виде последовательность для реализации генетического алгоритма выглядит следующим образом [7]:

1. Составляется популяция из $n$ особей.

2. Для каждой особи вычисляется ее приспособленность.

3. Выбираются родители с помощью какого-нибудь способа отбора.

4. Производится потомок, гены которого унаследованы от родителей.

5. Производится мутация потомка.

6. Повторяем 2-5, пока не достигнем нужного результата.

Естественный отбор будет основан на параметрах экосистемы, а именно - количество хищников, ландшафт и наличие пищи. Особи с наилучшими характеристиками будут выживать и передавать свои гены.

Далее определим параметры особей, которые будут передаваться по наследству. Имеет смысл передавать именно те параметры, которые неоднозначно влияют на выживаемость рыбы, т.к. если передавать по наследству, например, скорость передвижения, то она со временем будет расти, позволяя быстрее находить пищу и уплывать от угрозы. Перечислим эти параметры:

1. Минимальный размер для размножения. Нельзя однозначно сказать, как будет изменяться этот параметр при естественном отборе, но можно предположить, что он будет расти, т.к. у рыбы будет больше шанс выжить.

2. Разброс плавания - покажет, какая стратегия выгоднее - постоянно плавать в поисках пищи или преодолевать небольшие расстояния, экономя энергию.

3. Коэффициент потери энергии - влияет как на затраты, так и на восполнения энергии; предполагается, что он будет стремиться принять какое-то значение, близкое или равное оптимальному.

4. Страх к другим рыбам - покажет, имеет ли смысл особи не тратить энергию на попытку уплыть от незнакомой ей рыбы. Если хищная рыба не голодная или её жертва не попадает в поле зрения, то это сохранит энергию травоядной особи. Этот параметр существует только у травоядных рыб.

5. Порог голода - влияет на частоту потребления пищи рыбой. Параметр не является однозначным, т.к. энергия, получаемая от поедания растения или рыбы - фиксированная, и есть слишком часто, не усваивая полезную энергию и уничтожая большие запасы пищи, может быть бессмысленно. С другой стороны, чаще пополнять шкалу энергии, съедая все запасы растений или рыб, выгодно для выживания.

Особь будет наследовать случайным образом $k$ генов от первого родителя и $n-k$ от второго. После создания потомка он подвергается мутации, т.е. случайно выбранные гены с малой вероятностью изменяются на небольшую величину.

Перед запуском симуляции пользователь определяет начальные условия, влияющие на ландшафт, частоту появления водорослей и начальный размер популяций, при которых он хочет исследовать поведение экосистемы. Далее создаются популяции с различными генами.

\section{5. Языки и среда разработки}

В качестве основного языка программирования для разработки был взят С\# и использующая его среда разработки Unity, на основе которой разрабатываются графиче- 
ские приложения. C помощью Unity было создано приложение для симуляции экосистемы, а именно - классы для генерации ландшафта, классы, реализующие логику поведения и движения объектов рыб. Написан класс для настройки параметров экосистемы и класс для сбора информации о работе приложения. Она записывается в файл, который затем подвергается обработке на другом языке программирования - Python.

\section{6. Анализ полученной экосистемы}

Для анализа экосистемы ведется сбор данных о количестве особей в популяциях с определенным интервалом времени.

Для начала посмотрим, как ведет себя экосистема с обычным ландшафтом в отсутствии хищников. По оси $y$ отмечено количество особей популяции, по оси $x$ - время в секундах (рис. 8). Количество особей в популяции имеет периодический характер. Это можно объяснить тем, что популяция травоядных рыб зависит от популяции водорослей. При росте популяции рыб количество особей водных растений падает, что в свою очередь вызывает вымирание популяции рыб. Далее рассмотрим экосистему без хищников с ландшафтом пещер (рис. 9).

Пещеры служат ограничителем для чрезмерного поедания водорослей травоядными рыбами, поэтому здесь график травоядных особей реже пересекает график водорослей. Вымирание потребителей в данном случае наступает не из-за полного истребления популяции водорослей, а из-за невозможности найти достаточное пропитание в стенах пещер.

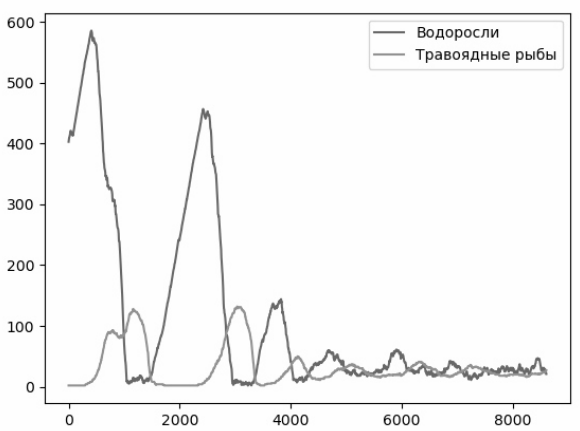

Рис. 8. Графики популяций, обычный ландшафт

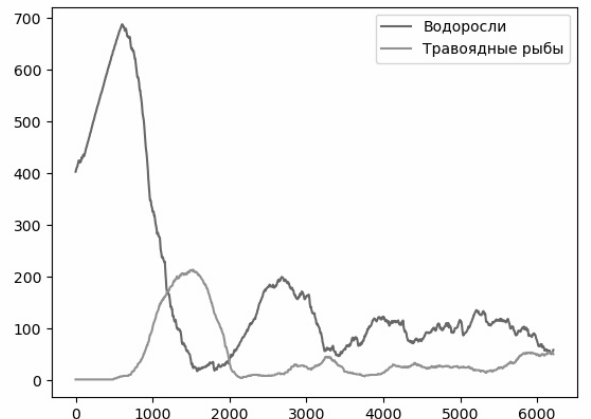

Рис. 9. Графики популяций, пещерный ландшафт

С наличием хищников экосистема с обычным ландшафтом ведёт себя следующим образом (рис. 10). Хищные рыбы контролируют популяцию травоядных рыб, поэтому популяция водорослей держится на отметке 200 - 300 особей. Далее - экосистема с пещерным ландшафтом (рис. 11). В случае пещерного ландшафта над популяцией травоядных идет контроль как со стороны хищников, так и со стороны ландшафта. 


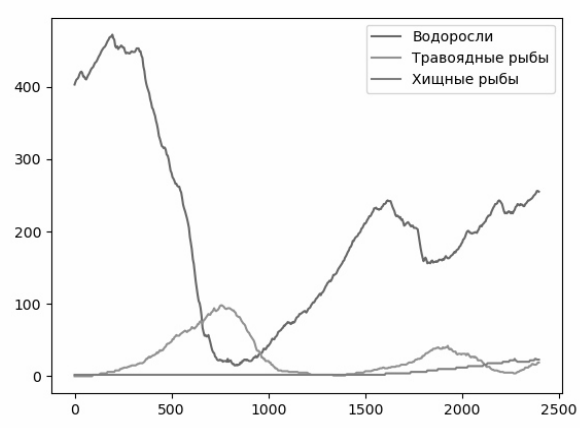

Рис. 10. Графики популяций, при обычном ландшафте, с хищниками

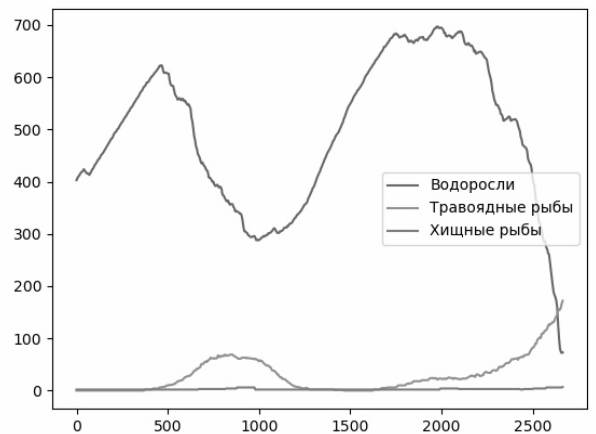

Рис. 11. Графики популяций при пещерном ландшафте, с хищниками

\section{Заключение}

Таким образом, была разработана симуляция экосистемы, обитателями которой являются водоросли, хищные и травоядные рыбы. Для живых обитателей был разработан искусственный интеллект на основе конечного автомата и введены элементы генетического алгоритма, позволяющие адаптироваться к меняющимся условиям. Была исследована зависимость популяций и их генов от параметров экосистемы, определяемых пользователем. Как показали эксперименты, при пещерном ландшафте популяции менее склонны к вымиранию. С обычным ландшафтом популяция травоядных рыб чрезмерно возрастает и поглощает всю без исключения пищу, что приводит либо к вымиранию всей популяции, либо к вымиранию большинства особей. Наличие хищников хоть и исправило положение, но при росте популяции хищных рыб с большой вероятностью вымирают травоядные. В дальнейшем планируется подробнее исследовать зависимость генов от параметров экосистемы и улучшить механизмы наследования и мутации, а также оптимизировать производительность программы в целом для больших исследований.

\section{ЛИТЕРАТУРА}

1. Sims $K$. Evolving Virtual Creatures // SIGGRAPH '94: Proceedings of the 21st annual conference on Computer graphics and interactive techniques. -1994 . - P. 15-22.

2. Википедия [Электронный ресурс]: Игра «Жизнь» URL: https://ru.wikipedia.org/wiki/Игра_«Жизнь». (дата обращения 1.05.2021).

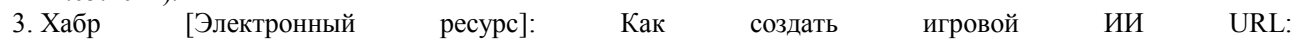
https://habr.com/ru/company/pixonic/blog/428892/. (дата обращения 27.04.2021).

4. Википедия [Электронный ресурс]: Бросание лучей URL: https://ru.wikipedia.org/wiki/Ray_casting. (дата обращения 2.05.2021).

5. Hyttinen T. Terrain synthesis using noise. - Tampere, 2017. $-54 \mathrm{p}$.

6. Shiffman D. The Nature Of Code [Электронный ресурc]: Chapter 9. The Evolution of Code URL: https://natureofcode.com/book/chapter-9-the-evolution-of-code/. (дата обращения 29.03.2021)

7. Панченко Т.В. Генетические алгоритмы: учебно-методическое пособие / под ред. Ю. Ю. Тарасевича. Астрахань: Издательский дом «Астраханский университет», 2007. - 87 с. 